\title{
IL-6 and IL-10 levels in the umbilical cord blood of newborns with a history of crack/cocaine exposure in utero: a comparative study
}

\author{
Níveis de IL-6 e IL-10 no sangue de cordão umbilical de recém-nascidos com \\ história de exposição intrauterina ao crack/cocaína: um estudo comparativo
}

Victor Mardini, ${ }^{1,2}$ Luis Augusto Rohde, ${ }^{1,2,3,4}$ Keila Maria Mendes Ceresér, ${ }^{2,5}$ Carolina de Moura Gubert, ${ }^{5}$ Emily Galvão da Silva, ${ }^{5}$

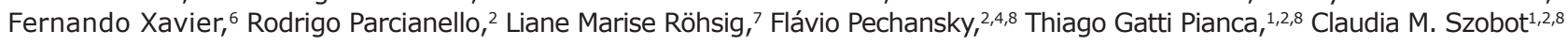

\begin{abstract}
Introduction: Prenatal cocaine exposure (PCE) is associated with neurobehavioral problems during childhood and adolescence. Early activation of the inflammatory response may contribute to such changes. Our aim was to compare inflammatory markers (IL-6 and IL-10) both in umbilical cord blood and in maternal peripheral blood at delivery between newborns with history of crack/cocaine exposure in utero and non-exposed newborns.

Methods: In this cross-sectional study, 57 newborns with a history of crack/cocaine exposure in utero (EN) and 99 non-exposed newborns (NEN) were compared for IL-6 and IL-10 levels. Sociodemographic and perinatal data, maternal psychopathology, consumption of nicotine and other substances were systematically collected in cases and controls.

Results: After adjusting for potential confounders, mean IL- 6 was significantly higher in EN than in NEN $(10,208.54,95 \%$ confidence interval $[95 \% \mathrm{CI}] 1,328.54-19,088.55$ vs. $2,323.03$, $95 \%$ CI 1,484.64-3,161.21; $p=0.007$; generalized linear model $[\mathrm{GLM}])$. Mean IL-10 was also significantly higher in EN than in NEN $(432.22,95 \%$ CI $51.44-812.88$ vs. 75.52 , 95\%CI $5.64-$ $145.39, \mathrm{p}=0.014 ; \mathrm{GLM})$. Adjusted postpartum measures of IL-6 were significantly higher in mothers with a history of crack/cocaine use $(25,160.05,95 \%$ CI $10,958.15-39,361.99$ vs. $8,902.14$, $95 \%$ CI 5,774.97-12,029.32; $p=0.007 ;$ GLM), with no significant differences for IL-10. There was no correlation between maternal and neonatal cytokine levels (Spearman test, $p \geq 0.28$ for all measures).

Conclusions: IL- 6 and IL-10 might be early biomarkers of PCE in newborns. These findings could help to elucidate neurobiological pathways underlying neurodevelopmental changes and broaden the range of possibilities for early intervention.

Keywords: Cytokines, pregnancy, crack cocaine, umbilical cord blood, newborn, interleukins.
\end{abstract}

\section{Resumo}

Introdução: A exposição pré-natal à cocaína está associada a problemas neurocomportamentais durante a infância e adolescência. A ativação precoce da resposta inflamatória pode contribuir para tais alterações. Nosso objetivo foi comparar marcadores inflamatórios (IL-6 e IL-10) no sangue do cordão umbilical e no sangue periférico materno na hora do parto, entre recém-nascidos expostos ao crack intraútero e recém-nascidos não expostos. Métodos: Neste estudo transversal, 57 recém-nascidos expostos ao crack intraútero (RNE) e 99 recém-nascidos não expostos (RNNE) foram comparados quanto aos níveis de IL-6 e IL-10. Dados sociodemográficos e perinatais, psicopatologia materna, consumo de nicotina e outras substâncias foram sistematicamente coletados em casos e controles.

Resultados: Após o ajuste para potenciais confundidores, a média de IL-6 foi significativamente maior nos RNE em comparação aos RNNE [10.208,54, intervalo de confiança (IC95\%) 1.328,54$19.088,55$ versus $2.323,03$, IC95\% $1.484,64-3.161,21 ; \mathrm{p}=$ 0,007 ; modelo linear generalizado (MLG)]. A média ajustada de IL-10 foi significativamente maior nos RNE do que nos RNNE $(432,2189$, IC95\% 51,44-812, 88 versus 75,52 , IC95\% 5,64$145,39, p=0,014 ; M L G)$. Medidas pós-parto ajustadas de IL-6 foram significativamente maiores nas mães que usaram de crack/cocaína (25.160,05, IC95\% 10.958,15-39.361,99 versus 8.902,14, IC95\% 5.774,97-12.029,32; $p=0,007$; MLG), sem diferenças significativas para IL-10. Não houve correlação entre níveis maternos e neonatais de citocinas (teste de Spearman, $\mathrm{p}$ $\geq 0,28$ para todas as medidas).

Conclusões: IL-6 e IL-10 podem ser biomarcadores precoces da exposição pré-natal a cocaína em recém-nascidos. Esses resultados podem ajudar a elucidar as vias neurobiológicas subjacentes a alterações do desenvolvimento e aumentar a gama de possibilidades para intervenção precoce.

Descritores: Cocaína crack, interleucinas, recém-nascido, gestação.

\footnotetext{
${ }^{1}$ Serviço de Psiquiatria da Infância e da Adolescência (SPIA), Hospital de Clínicas de Porto Alegre (HCPA), Porto Alegre, RS, Brazil. ${ }^{2}$ Programa de Pós-Graduação em Medicina: Psiquiatria, Universidade Federal do Rio Grande do Sul (UFRGS), Porto Alegre, RS, Brazil. ${ }^{3}$ Instituto Nacional de Psiquiatria do Desenvolvimento (INPD), São

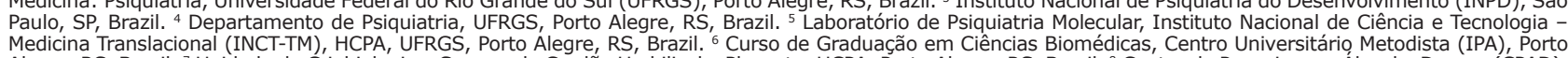
Alegre, RS, Brazil. 7 Unidade de Criobiologia e Sangue de Cordão Umbilical e Placenta, HCPA, Porto Alegre, RS, Brazil. ${ }^{8}$ Centro de Pesquisa em Álcool e Drogas (CPAD), Alegre, RS, Brazil.7 Unidade de Criobiol,
HCPA, UFRGS, Porto Alegre, RS, Brazil.

Financial support: Coordenação de Aperfeiçoamento de Pessoal de Nível Superior (CAPES), Fundação de Amparo à Pesquisa do Estado do Rio Grande do Sul (FAPERGS), and Fundo de Incentivo à Pesquisa e Eventos - Hospital de Clínicas de Porto Alegre (FIPE-HCPA). Together, these institutions provided financial support for study development, laboratory testing, and all other expenses.

Submitted Dec 02 2015, accepted for publication Dec 182015.

Conflicts of interest: Luis Augusto Rohde has been on the speakers' bureau and/or acted as a consultant for Eli Lilly, Janssen-Cilag, Novartis, and Shire, and receives royalties from Oxford Press and Artmed. The ADHD and Juvenile Bipolar Disorder Outpatient Programs chaired by Luis Augusto Rohde has received unrestricted royalties from Oxford Press and Artmed. The ADHD and Juvenile Bipolar Disorder Outpatient Programs chaired by Luis Augusto Rohde has received unrestricted
educational and research support from the following pharmaceutical companies: Eli Lilly, Janssen-Cilag, Novartis, and Shire. Claudia M. Szobot has been on the educational and research support from the following pharmaceutical companies: Eli Lily,
speakers' bureau of Novartis. The other authors have no conflicts of interest to declare.

Suggested citation: Mardini V, Rohde LA, Ceresér KM, Gubert CM, da Silva EG, Xavier F, et al. IL-6 and IL-10 levels in the umbilical cord blood of newborns with a history of crack/cocaine exposure in utero: a comparative study. Trends Psychiatry Psychother. 2016;38(1):40-49. http://dx.doi.org/10.1590/2237-6089-2015-0081
} 


\section{Introduction}

Prenatal cocaine exposure (PCE) is considered a marker for potential development of neurobehavioral problems soon after delivery and during childhood/adolescence. ${ }^{1-3}$ The harmful effects of intrauterine cocaine exposure are not restricted to mental illness. Changes in the cardiovascular system have been reported in studies using animal models. ${ }^{4}$ In humans, changes have been observed in the neuroendocrine system and metabolic processes, with increased weight gain and childhood obesity. ${ }^{5,6}$ Taken together, these data suggest a hypothesis that cocaine exposure can have systemic effects. Notwithstanding, the pathways underlying these systemic effects in exposed newborns remain uncertain. One possible explanation that is consistent with other conditions ${ }^{7-14}$ is early activation of the inflammatory response.

Studies using neurobiological markers have suggested that cocaine dependence is a chronic stress state. ${ }^{15}$ For example, Fox et al. ${ }^{16}$ compared 28 adults with cocaine dependence to 27 social drinkers and demonstrated an elevated inflammatory state, as measured by interleukin-10 (IL-10), among other factors. Another report found higher levels of IL-1 $1 \beta$, TNF-a, and IL-10 in the circulation of 53 male crack/cocaine addicts than in 50 controls. ${ }^{17}$

Cocaine and its metabolites readily cross the placenta, reaching fetal tissues at high concentrations ${ }^{18,19}$ and deregulating fetal homeostasis. A study of the effects of PCE on infant hypothalamic-pituitary-adrenal (HPA) axis activity and reactivity at 7 months of infant age revealed that exposed infants had a high amplitude trajectory of cortisol reactivity compared to non-cocaineexposed infants. ${ }^{20}$ Sustained stress triggers a series of changes in cytokines. Chronic stress leads to activation of the HPA axis, sympathetic nervous system axis, and vagus fibers, provoking secretion of glucocorticoids, catecholamines, and acetylcholine, thereby disturbing cytokine homeostasis. ${ }^{14}$

It is difficult to distinguish which effects during child and adolescent development might be due to PCE and which may be due to other adverse conditions. Cocaineexposed infants are at higher levels of environmental risk and experience unstable caregiving. ${ }^{21}$ This highlights the importance of identifying neurobiological markers closer in time to intrauterine exposure. Studies focusing specifically on crack/cocaine - or cocaine - exposure and cytokines in newborns are scarce. Only one study exists, but cytokine levels were not its primary outcome measure and the sample size was small (five exposed infants and five controls). ${ }^{22}$

It is known that the neonatal immune system is immature relative to the adult immune system. ${ }^{23}$
Specifically, anti-inflammatory Th2 response predominates, which is probably a consequence of the gestational immunosuppression that is necessary to maintain the fetus without it being rejected as a foreign body. ${ }^{24}$ There is also a relative absence of $\mathrm{IL}-12$ production until the end of infancy, favoring Th2 response. ${ }^{23}$ During pregnancy, a dynamic and delicate balance between inflammatory and anti-inflammatory cytokines is expected, to protect growth and development of both fetus and placenta. ${ }^{24}$

Given the close relationship between cocaine exposure and inflammatory response, the objective of this study is to evaluate markers of inflammation (IL-6 and IL-10) in newborns with a history of crack/ cocaine exposure in utero (exposed newborns, EN) and to compare them with non-exposed newborns (NEN), measuring these markers in umbilical cord blood (UCB). This strategy makes it possible to identify biomarkers very early in the neurodevelopment process, before exposure to other external adverse conditions has occurred. The hypothesis is that greater activation of the inflammatory response will be observed in the newborns with a history of crack/cocaine exposure in utero. A secondary objective is to evaluate the same markers in the mothers of these newborns during the postpartum period.

\section{Materials and methods}

Data were collected at the Hospital de Clínicas de Porto Alegre (HCPA) and the Hospital Materno Infantil Presidente Vargas (HMIPV), both in the city of Porto Alegre, Brazil, from January 2012 to September 2013. Both facilities are teaching hospitals as well as centers of excellence for high-risk pregnancies. All mothers provided written informed consent for participation, and the project was approved by the Research Ethics Committees of both hospitals.

\section{Study design and sample}

This was a cross-sectional study. The factor under study was history of intrauterine exposure to crack/ cocaine and the outcome measures were serum levels of the cytokines interleukin (IL)- 6 and IL-10 in UCB. A secondary outcome was measurement of the same markers assayed in the serum of these newborns' mothers.

Mother/newborn dyads with a history of crack/ cocaine exposure underwent consecutive sampling at HMIPV. Mothers were questioned about use of substances of abuse at admittance to the hospital. 
During the study period, 2,228 births took place at HMIPV, and 105 mothers (4.7\%) were identified as having a history of crack/cocaine use. Sixty-two (59\%) of these 105 mothers were invited to take part in the study and we ultimately analyzed the UCB of 57 newborn infants (54\%). The losses occurred were due to a variety of reasons, including refusal to take part, no report of past crack/cocaine use at the time of delivery, and absence of the technical conditions necessary for UCB collection.

To ascertain the profile of the pregnant crack/ cocaine users who were not included in the sample $(n=43 ; 41 \%)$, we used medical records to compare participants and non-participants in terms of maternal age, educational attainment, ethnicity, presence of a partner, prenatal treatment status, mode of delivery, and presence of infectious diseases (hepatitis C, syphilis, and/or HIV). We also compared Apgar scores at 1 and 5 minutes, newborn weight, and gestational age (GA) at neonatal examination. Newborn weight was significantly lower for the infants of mothers who did not participate in the study $(2,653.46$ vs. $2,878.09 \mathrm{~g}, \mathrm{p}=0.02)$, as were GA (37.30 [standard deviation $\{\mathrm{SD}\}=2.50$ ] vs. $38.64[S D=2.4]$ weeks, $p=0.02$ ) and prenatal care attendance $(p=0.02)$, with no other significant intergroup differences (data available upon request).

The control sample of newborns and mothers without a history of cocaine exposure was recruited from a group of pregnant women who participated in the HCPA umbilical cord and placental blood bank project (Banco de Sangue de Cordão Umbilical e Placentário, BSCUP). During the study period, 6,312 births took place at the HCPA. Of this total, 1,050 pregnant women (16.6\%) were screened for inclusion using a systematic approach (Monday through Friday, from 08:00 to 23:00). The Foundation for the Accreditation of Cellular Therapy (FACT) criteria $^{25}$ establish technical regulations for the operation of laboratories that process hematopoietic stem cells (HSC) from bone marrow and peripheral blood and for umbilical cord and placental blood banks. According to these criteria, 770 (73.3\%) of the women screened were eligible for data collection, but the umbilical cords of 112 (14.5\%) of the 770 eligible women were rejected by the BSCUP due to low cellularity and/ or low blood volume. These mothers and umbilical cords were eligible for use in our control group. Rejected bags were sent to the laboratory where the present study was underway for processing and storage. Of the 112 potential participants, $99(88.3 \%)$ were actually enrolled on the study as controls. Losses were due to refusal to participate in the survey or because the mother and newborn had been discharged from the hospital before the research team could invite them to participate.
In order to verify the representativeness of the mothers included in the control group we randomly selected 68 (10.3\%) pregnant women whose UCB had been collected during the study period and kept at the BSCUP and reviewed their medical records. We compared the age, ethnicity, prenatal care, and mode of delivery of these women to those of mothers included in the study control group. We also compared these groups in terms of infant sex, need for hospitalization, Apgar scores at 1 and 5 minutes, birth weight, GA at neonatal examination, and classification of size for GA. There were significant differences in newborn weight $(3,144.79$ $[S D=438.39] \mathrm{g}$ in the study controls vs. 3,357.35 $[S D=418.87] \mathrm{g}$ in other donors; $\mathrm{p}=0.002$ ) and $\mathrm{GA}$ at neonatal examination (38.86 [SD $=1.24]$ weeks in study newborns vs. 39.26 [SD $=1.15$ ] weeks among newborns not included; $p=0.04$ ). No other significant differences were found (data available upon request).

The inclusion criteria for the mothers in the case group were history of crack/cocaine use and age 18-45 years, and exclusion criteria were inability to understand and complete the neuropsychiatric questionnaires in the immediate postpartum period. The inclusion and exclusion criteria for controls were based on the FACT criteria $^{25}$ (Foundation for the Accreditation of Cellular Therapy, 2013). All mothers included in the control group were confirmed as non-drug users by their history and urinary tests (Bioeasy ${ }^{\circledR}$ cocainetest, Alere ${ }^{\mathrm{TM}}$, Brazil).

\section{Instruments and variables}

The independent variable was a history of crack/ cocaine use during pregnancy. Potential confounders were: maternal intelligence quotient (IQ), maternal psychopathology, use of other psychoactive substances, and demographic and perinatal data. Maternal IQ was estimated using the cube and vocabulary subtests of the Wechsler Adult Intelligence Scale, 3rd edition (WAISIII). ${ }^{26,27}$ Maternal psychopathology was assessed using the Mini International Neuropsychiatric Interview (MINI), Brazilian version 5.0.0/ Diagnostic and Statistical Manual of Mental Disorders, 4th edition (DSM-IV)/Current. ${ }^{28}$ Use of psychoactive substances was evaluated with the Alcohol, Smoking and Substance Involvement Screening Test (ASSIST), ${ }^{29}$ as previously used by our group. ${ }^{30}$ By taking these measures, we were able to evaluate substance use in the 3 months prior to delivery. Socioeconomic level was assessed using criteria set forth by Associação Brasileira de Anunciantes (ABA) and Associação Brasileira de Institutos de Pesquisa de Mercado (ABIPEME), and dichotomized into high socioeconomic status (classes $A$ and $B$ ) or low socioeconomic status (classes C, D, and E). ${ }^{31}$ Age, self-reported ethnicity, 
marital status, and other sociodemographic variables were systematically collected using a standard form. Ethnicity was dichotomized as non-white or white. The following neonatal variables were obtained by review of medical records: weight, 1 and 5 minute Apgar scores, GA at neonatal examination, sex, need for hospitalization, and GA classification. Data on mothers' clinical status (syphilis, HIV, and/or hepatitis C), mode of delivery, and prenatal care were also collected from medical records. The outcome measures level of IL- 6 and level of IL-10 in UCB and maternal blood were collected and assayed as described below.

\section{Blood collection and processing}

Total blood $(10 \mathrm{~mL})$ samples were collected by venipuncture into an anticoagulant-free vacuum tube. Immediately after collection, blood samples were centrifuged at $4000 \mathrm{rpm} / \mathrm{min}$ for $10 \mathrm{~min}$ and serum (from patients and controls) or plasma (from newborns) was aliquoted, labeled, and stored at $-80{ }^{\circ} \mathrm{C}$ until the time of testing.

\section{Cytokine measurement}

Cytokine concentrations were determined via flow cytometry using the $\mathrm{BD}^{\mathrm{TM}}$ Cytometric Bead Array (CBA), Human IL-6, and IL-10 Enhanced Sensitivity Flex Set (BD Biosciences, San Diego, CA, USA). Sample processing and data analysis were performed according to the manufacturer's instructions. Briefly, homogenate samples and standard curves ranging from 274 to $200,000 \mathrm{fg} / \mathrm{mL}$ of each cytokine were incubated with the three cytokine capture beads for $2 \mathrm{~h}$, then the Human Detection Reagent was added and incubated for another 2 h. The Enhanced Sensitivity Detection Reagent was washed twice and then incubated for $1 \mathrm{~h}$. Subsequently, samples were washed and sample data acquired using a FACSCalibur flow cytometer (BD Biosciences, San Diego, CA, USA). All incubations were performed at room temperature, protected from light. Results were generated in graphical and tabular form using BD CBA FCAP Array ${ }^{\mathrm{TM}}$ Software v.3 (BD Biosciences, San Diego, CA, USA) and expressed as $\mathrm{fg} / \mathrm{mL}$.

\section{Statistical analysis}

Normally distributed categorical and quantitative variables were analyzed with the chi-square test and Student's $t$ test for independent samples respectively. When distribution was not normal, the Mann-Whitney $U$ test was used instead and values were expressed as medians and ranges. The main outcome measure was evaluated using generalized linear model (GLM) analyses (gamma distribution), and confounders were chosen for investigation on the basis of a statistical criterion (association with both study factor and outcome measure at a significance level of $p \leq 0.2$ ). Confounders that met this statistical criterion were entered into the model together with each outcome variable. The significance level was set at $p \leq 0.05$. Data were processed and analyzed using PASW Statistics 18.0.

\section{Results}

The sample comprised 57 newborns with a history of prenatal crack/cocaine exposure and 99 with no history of exposure. Table 1 lists a selection of characteristics of the newborns and their mothers. Unadjusted IL levels (median [minimum and maximum] and mean [SD]) are displayed in Table 1 . There were no reports of use of intravenous drugs, club drugs, or hallucinogens.

\section{Main outcome variable: IL levels in UCB}

In the GLM analyses for IL-6, results were adjusted for intensity of alcohol, tobacco, and cannabis use in the last 3 months before delivery, maternal ethnicity, presence of any maternal psychopathology, and 5-minute Apgar score. Adjusted mean IL-6 was significantly higher in newborns with a history of crack/cocaine exposure in utero $(10,208.54,95 \% C I 1,328.54-19,088.55)$ than in non-exposed newborns $(2,323.03,95 \%$ CI $1,484.64$ $3,161.21 ; p=0.007)$, as shown in Figure 1 . Besides history of crack/cocaine exposure, the following variables were also associated with significant differences in IL-6 levels: 5-minute Apgar score $(p<0.001)$, cannabis use $(p=0.01)$, and ethnicity $(p=0.004)$. For GLM analysis of IL-10, results were adjusted for intensity of alcohol, tobacco, and cannabis use in the last 3 months before delivery, maternal ethnicity, presence of any maternal psychopathology, 5-minute Apgar score, infant weight, maternal infectious disease (HIV, syphilis, and/or hepatitis C), and educational attainment. Adjusted mean IL-10 was significantly higher in newborns with a history of crack/cocaine exposure in utero (432.22, $95 \%$ CI $51.44-812.88)$ in comparison to non-exposed newborns (75.52, 95\%CI 5.64-145.39, $p=0.014$ ), as shown in Figure 2. In addition to history of crack/cocaine exposure, 5-minute Apgar score also contributed to the IL-10 model ( $95 \% \mathrm{CI}-0.55$ to $-0.01, \mathrm{p}=0.042$ ).

There were no correlations between IL- 6 and IL-10 levels in maternal serum or in UCB plasma (all $p \geq 0.28$; Spearman correlation), whether for inter-group or intragroup comparisons. However, there was a significant 
Table 1 - Sociodemographic data, clinical characteristics and IL levels of pregnant crack/cocaine users and their newborns in comparison to a control group

\begin{tabular}{|c|c|c|c|}
\hline Infant variables & Cases $(n=57)$ & Controls $(n=99)$ & $\mathbf{p}$ \\
\hline Weight $(\mathrm{g})$, mean (SD) & $2,882.15(473.32)$ & $3,144.80(439.39)$ & 0.001 \\
\hline 1-minute Apgar, mean (SD) & $7.8(2.12)$ & $8.41(1.31)$ & 0.06 \\
\hline 5-minute Apgar, mean (SD) & $8.94(1.24)$ & $9.38(0.74)$ & 0.007 \\
\hline Gestational age, weeks (estimated at neonatal examination), mean (SD) & $38.58(2.06)$ & $38.86(1.24)$ & 0.37 \\
\hline Male sex, n (\%) & $28(50.9)$ & $46(46.5)$ & 0.72 \\
\hline Need for hospitalization, $\mathrm{n}(\%)$ & $36(67.9)$ & $15(15.5)$ & $<0.001$ \\
\hline \multicolumn{4}{|l|}{ Classification for gestational age, n (\%) } \\
\hline Adequate & $43(87.8)$ & $75(77.3)$ & \\
\hline Small & $4(8.2)$ & $16(16.5)$ & 0.31 \\
\hline Large & $2(4.1)$ & $6(6.2)$ & \\
\hline Maternal variables & Cases $(n=57)$ & Controls $(n=99)$ & $\mathbf{p}$ \\
\hline \multicolumn{4}{|l|}{ Ethnicity, n (\%) } \\
\hline White & $17(32.1)$ & $74(76.3)$ & $<0.001$ \\
\hline Non-white & $36(67.9)$ & $23(23.7)$ & \\
\hline Age (years), mean (SD) & $27.00(5.76)$ & $26.17(5.87)$ & 0.39 \\
\hline $\mathrm{IQ}$, mean (SD) & $77.39(8.75)$ & $84.17(9.59)$ & $<0.001$ \\
\hline \multicolumn{4}{|l|}{ Socioeconomic status, n (\%) } \\
\hline High (class A or B) & $6(11.8)$ & $18(18.8)$ & 0.19 \\
\hline Low (class C, D, or E) & $45(88.2)$ & $78(81.3)$ & \\
\hline \multicolumn{4}{|l|}{ Educational attainment, n (\%) } \\
\hline Some primary, completed primary, or some secondary education & $39(81.3)$ & $51(53.1)$ & \\
\hline Completed secondary, some higher, or completed higher education & $9(18.8)$ & $45(53.1)$ & 0.002 \\
\hline Prenatal care, $\mathrm{n}(\%)^{*}$ & $36(73.5)$ & $99(100)$ & $<0.001$ \\
\hline Presence of infectious diseases, $\mathrm{n}(\%) *$ (syphilis, HIV, and/or hepatitis C) & $26(46.4)$ & 0 & $<0.001$ \\
\hline Mode of delivery (Cesarean delivery), n (\%) & $19(35.2)$ & $34(35.1)$ & 1.00 \\
\hline Marital status (married/cohabiting), n (\%)* & $29(50.9)$ & $94(94.9)$ & $<0.001$ \\
\hline $\begin{array}{l}\text { Drug use by mothers during pregnancy - ASSIST total score, median } \\
\text { and range } t\end{array}$ & Cases & Controls & \\
\hline Total score for nicotine ${ }^{\ddagger}$ (cases, $\mathrm{n}=32$; controls, $\mathrm{n}=22$ ) & $17.50(0-31)$ & $0.00(0-39)$ & $<0.001$ \\
\hline Total score for alcohol ${ }^{\ddagger}$ cases, $\mathrm{n}=28$; controls, $\mathrm{n}=33$ ) & $6.00(0-33)$ & $0.00(0-13)$ & $<0.001$ \\
\hline Total score for cannabis ${ }^{\ddagger}$ cases, $n=26$; controls, $n=26$ ) & $0.00(0-25)$ & - & - \\
\hline \multicolumn{4}{|l|}{ Substance use in the last 3 months prior to delivery, $\mathbf{n}(\%)$} \\
\hline Nicotine & Cases $(n=32)$ & Controls $(n=22)$ & \\
\hline Daily/almost every day & $22(68.75)$ & $5(22.7)$ & $<0.001$ \\
\hline Weekly & $1(0.03)$ & - & \\
\hline Monthly & $4(0.13)$ & - & \\
\hline Once or twice & $2(0.06)$ & $17(77.3)$ & \\
\hline Never & $3(0.09)$ & - & \\
\hline Alcohol & Cases $(n=28)$ & Controls $(n=33)$ & \\
\hline Daily/almost every day & $2(7.14)$ & - & $<0.001$ \\
\hline Weekly & $10(35.70)$ & - & \\
\hline Monthly & $3(10.70)$ & - & \\
\hline Once or twice & $4(14.30)$ & $5(15.20)$ & \\
\hline Never & $9(32.10)$ & $28(84.80)$ & \\
\hline Crack/cocaine & Cases $(n=32)$ & Controls $(n=32)$ & \\
\hline Daily/almost every day & $9(28.1)$ & - & - \\
\hline Weekly & $13(40.6)$ & - & - \\
\hline Monthly & $3(9.4)$ & - & - \\
\hline Once or twice & $1(3.1)$ & - & - \\
\hline Never & $6(10.5)$ & - & - \\
\hline
\end{tabular}




\begin{tabular}{|c|c|c|c|}
\hline Cannabis & Cases $(n=26)$ & Controls $(n=26)$ & \\
\hline Daily/almost every day & $2(7.7)$ & - & - \\
\hline Weekly & $5(19.2)$ & - & - \\
\hline Monthly & $2(7.7)$ & - & - \\
\hline Once or twice & $1(3.8)$ & - & - \\
\hline Never & $16(61.5)$ & - & - \\
\hline Presence of current psychopathology in mothers, $\mathbf{n}(\%)$ & Cases $(n=41)$ & Controls $(n=96)$ & \\
\hline Suicide risk & $13(31.70)$ & $9(9.78)$ & 0.002 \\
\hline Posttraumatic stress disorder*§ & $4(10.00)$ & $0(0.00)$ & 0.007 \\
\hline Antisocial personality disorder* & $9(21.43)$ & $0(0.00)$ & $<0.001$ \\
\hline MINI positive for any diagnoses & $25(61.0)$ & $32(33.3)$ & 0.005 \\
\hline Unadjusted UCB IL levels $\$$ & Cases $(n=45)$ & Controls $(n=93)$ & \\
\hline \multicolumn{4}{|l|}{ IL-6 in UCB } \\
\hline Median (minimum and maximum) & $\begin{array}{c}2,013.95 \\
(0-583,892.27)\end{array}$ & $\begin{array}{c}737.61 \\
(0-29,649.70)\end{array}$ & 0.004 \\
\hline Mean (SD) & $\begin{array}{c}36,885.01 \\
\left(1.17186 \times 10^{5}\right)\end{array}$ & $\begin{array}{c}2,049.53 \\
(4,027.94)\end{array}$ & \\
\hline \multicolumn{4}{|l|}{ IL10 at UCB } \\
\hline Median (minimum and maximum) & $\begin{array}{c}109.93 \\
(0-2,445.83)\end{array}$ & $9.14(0-1,016.84)$ & $<0.001$ \\
\hline Mean (SD) & $335.62(591.70)$ & $47.41(121.43)$ & \\
\hline Unadjusted IL levels at immediate postpartum, mothers $\$$ & Cases $(n=48)$ & Controls $(n=83)$ & \\
\hline \multicolumn{4}{|l|}{ Maternal IL-6 levels } \\
\hline Median (minimum and maximum) & $\begin{array}{c}3,022.09 \\
(0-1,201,174.90)\end{array}$ & $\begin{array}{c}6,664.98 \\
(62.40- \\
171,500.39)\end{array}$ & 0.11 \\
\hline Mean (SD) & $\begin{array}{c}43,591.24 \\
\left(1.77086 \times 10^{5}\right)\end{array}$ & $\begin{array}{c}12,981.55 \\
(21,877.39)\end{array}$ & \\
\hline \multicolumn{4}{|l|}{ Maternal IL-10 levels } \\
\hline Median (minimum and maximum) & $\begin{array}{c}195.14 \\
(0-34,305.03)\end{array}$ & $\begin{array}{c}310.36 \\
(0-9,441.20)\end{array}$ & 0.12 \\
\hline Mean (SD) & $\begin{array}{c}1,215.63 \\
(4,954.13)\end{array}$ & $\begin{array}{c}1,105.25 \\
(1,894.63) \\
\end{array}$ & \\
\hline
\end{tabular}

difference between sexes in the case group (MannWhitney $U$ ), where median IL-6 was significantly higher in boys (median $=6,726.20$; range $=177.63-583,892.27$; interquartile range $=990.30-18,429.06 ; \mathrm{n}=19$ ) than in girls (median $=856.92$; range $=56.64-203,797.48$; interquartile range $=597.13-3,017.68 ; n=24 ; p=0.022$ ). Although the median IL-10 level was also higher in newborn boys with a history of crack/cocaine exposure in utero than in exposed girls (196.16 vs. 68.16), this difference did not attain statistical significance $(p=0.14)$. Interestingly, we found no significant differences for IL-10 $(p=0.42)$ or IL-6 $(p=0.33)$ when analyzing the control newborns in isolation. Although the result for sex of newborns did not meet the statistical criterion for entry into the multivariate analysis, we conducted the same GLM for both IL-10 and IL-6 in UCB adding newborn sex as an additional variable. No major changes to the IL- 6 model resulted. However, newborn sex did make a significant contribution to the IL-10 model (Wald=18.42, p 50.001 ), while the predictor variable, history of exposure to crack/cocaine during pregnancy and the confounder 5-minute Apgar score, remained significant (data available upon request).

\section{Secondary outcome measures: maternal IL levels in the immediate postpartum period}

According to GLM analysis, using a model including intensity of alcohol and tobacco use in the last 3 months before delivery, mode of delivery, and maternal ethnicity, IL-6 measures in the immediate postpartum period were significantly higher in mothers with a history of crack/cocaine use $(25,160.05$, 95\%CI 10,958.15$39,361.99)$ than in control mothers $(8,902.14,95 \% \mathrm{CI}$ 
$5,774.97-12,029.32, p=0.007)$, as shown in Figure 3 . Intensity of alcohol use and tobacco use and mode of delivery were also significant in the model $(p=0.010$, 0.001 , and $<0.001$, respectively). Univariate analysis found no difference in IL-10 levels between case and control groups expressed as median (minimummaximum) (195.14 [0-34,305.03] vs. 310.36 [0$9,441.20]$ respectively; $p=0.12$ ). The confounders entered into the model for IL-10 were mode of delivery, estimated IQ, and intensity of tobacco use in the last 3 months before delivery. None of the variables attained significance, and there was no difference in adjusted mean IL-10 between exposed and non-exposed mothers $(1,086.40$ vs. $1,200.42$ respectively, $p=0.83)$.

\section{Discussion}

This study analyzed early neurobiological markers involved in inflammatory activation in newborns with a history of crack/cocaine exposure in utero. These markers were measured at delivery, when the newborn has not yet been exposed to other stressors. We found a significant increase in inflammatory activation in newborns with a history of intrauterine crack/ cocaine exposure, as assessed both by IL-6 and IL-10 measures; and this finding remained after adjusting for confounders. In pregnant women who reported crack/ cocaine use, inflammatory activation (measured by IL-6) was also observed, considering confounders. Among the exposed newborns, male newborns seemed particularly vulnerable to inflammatory activation. Arriving at an explanation for our findings is complex and may involve a variety of mechanisms that interact with each other.

Other studies have evaluated peripheral inflammatory markers in cocaine users, and have found a trend toward greater inflammatory activation. ${ }^{16,17}$ However, studies specifically investigating mother/newborn dyads exposed to crack/cocaine are scarce, limiting the scope for comparison of our findings. Cocaine may be linked with inflammation resulting from the neuronal damage or death that it causes. ${ }^{17}$ In terms of neuronal death, crack/cocaine would be more hazardous than snorted cocaine because of the byproducts of pyrolysis, which generates anhydroecgonine methyl ester. ${ }^{32}$ Cocaine administration increases levels of dopamine and its metabolites, resulting in exacerbated production of reactive oxygen species. ${ }^{33,34}$ Oxidative stress per se promotes inflammation, ${ }^{35}$ triggering generation of proinflammatory cytokines and chemokines. Additionally, cocaine has a vasoconstrictor effect on the uterine artery, resulting in fetal hypoxia and increased catecholamine release, thereby exposing the developing embryo/fetus

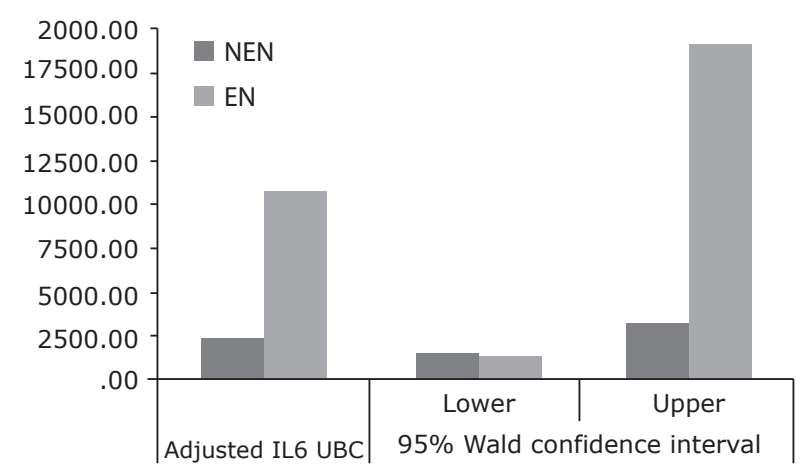

Figure 1 - Adjusted mean IL- 6 in the umbilical cord blood of newborns with a history of crack/cocaine exposure during pregnancy (EN; case group) compared to controls (NEN); mean adjusted for intensity of maternal alcohol, tobacco, and cannabis use in the last 3 months before delivery, maternal ethnicity, presence of any maternal psychopathology, and 5-minute Apgar score.

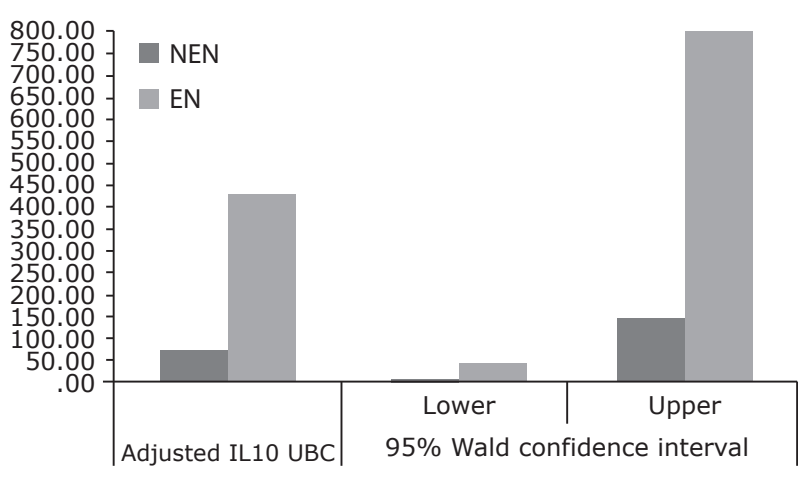

Figure 2 - Adjusted mean IL-10 in the umbilical cord blood of newborns with a history of crack/cocaine exposure during pregnancy (EN) compared to controls (NEN); mean adjusted for intensity of maternal alcohol, tobacco, and cannabis use in the last 3 months before delivery, maternal ethnicity, presence of any maternal psychopathology, 5-minute Apgar score, newborn weight, maternal educational attainment, and maternal infectious diseases (HIV, syphilis, or hepatitis C).

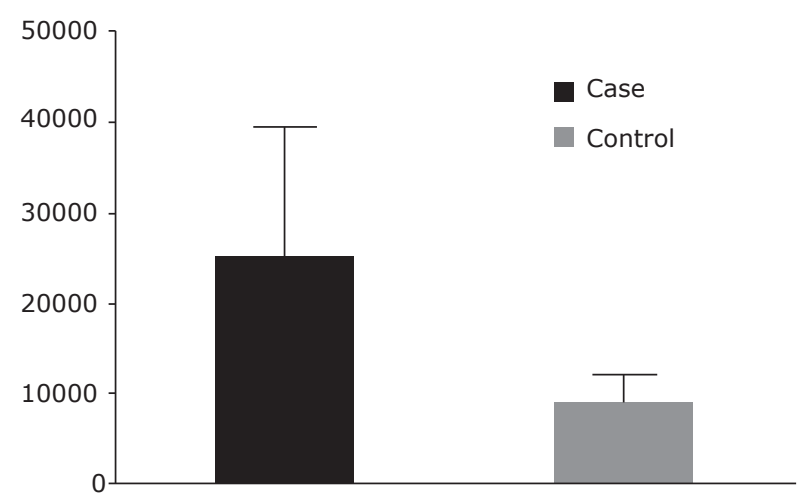

Figure 3 - IL-6 levels in the peripheral blood of women with a history of crack/cocaine use vs. control mothers. Mean IL-6 adjusted for intensity of alcohol and tobacco use in the last 3 months before delivery, mode of delivery, and maternal ethnicity. 
to a state of stress. ${ }^{20}$ This stress on the fetus would cause disturbances in cytokine homeostasis through activation of the HPA axis, sympathetic nervous system, and fibers of the vagus nerve. ${ }^{14,36}$ These factors may have contributed to the inflammatory activation seen in newborns with a history of crack/cocaine exposure in utero. Although our measures were "peripheral," there is communication between the central nervous system, the hormonal system and the innate immune system. ${ }^{37,38}$ The repercussions of inflammatory activation on neurodevelopment, the HPA axis, and epigenetics have recently been discussed elsewhere. ${ }^{39,40}$ Our results corroborate findings reported by Glover, ${ }^{41}$ who stated that cytokines are potential mediators for explaining the behavioral and cognitive effects of prenatal stress on the fetus and child. Studies have demonstrated the role of proinflammatory cytokines in several disorders, including depression and anxiety, as well as their role in cognitive function. Abnormalities in immune function have been reported in neurodevelopmental disorders. ${ }^{40}$

We found no correlation between maternal and neonatal IL-6 and IL-10 levels, whether in inter-group or intra-group comparisons. In other words, our results show that the reactions of pregnant women and their newborns are different. For example, we did not find any difference in IL-10 levels in pregnant women, but we did detect a difference in UCB measures, even with a smaller sample size. Developmental changes in immune and neuroendocrine function mediate perception and physiology of stress with effects that last throughout life. ${ }^{40,41}$ It is to be expected that pregnant women who use crack/cocaine will exhibit different responses in comparison with their newborns, because of the accumulation of stressors to which they are exposed throughout the course of their lives, coupled with the need to adapt to these factors. Our study, for example, detected several other chronic stressors (some prior to pregnancy) in those who reported crack/cocaine use when compared to controls (Table 1). Our findings agree with previous studies reporting that gestational stress is associated with greater inflammatory activation, ${ }^{42-44}$ which places newborns in a more vulnerable position, either because of the intensity of activation or because of changes in IL- 6 and IL-10 levels. Furthermore, boys with a history of crack/cocaine exposure in utero were significantly more likely to exhibit increased IL levels than girls. This finding is also in agreement with other studies. ${ }^{45,46}$

Thus, this study may contribute to the search for neurobiological markers of the future clinical and/ or neuropsychiatric repercussions of intrauterine crack/cocaine exposure demonstrated in previous research. ${ }^{1,3}$ These types of clinical changes, which persist into adulthood, have been understood through the developmental programming model and the telomere shortening phenomenon, with repercussions for generations to come. ${ }^{40,47-49}$ Knowing that exposure to cocaine alters corticostriatal gene expression, ${ }^{50}$ which also changes the stress response, we can expect these newborns to develop a more active warning system, leaving them vulnerable to addictive behavior. Although we did not assess cerebral morphology, studies have suggested an inverse association between IL- 6 levels and hippocampal volume. ${ }^{51,52}$ These changes in the hippocampus may contribute to the cognitive deficits observed in infants, toddlers, and children exposed to cocaine in utero. ${ }^{53-57}$ In an animal model, gestational cocaine exposure induced significant changes to the electrophysiological properties of hippocampal neurons. ${ }^{58}$ Intrauterine exposure to crack/cocaine could leave an immunological scar, making these infants vulnerable to physical and/or psychiatric disorders throughout life. This study helps to elucidate neurobiological mechanisms underlying these phenomena and contributes research topics of interest for future interventions. So far no evidence has been found to support treatments directed at the immune system from the psychiatric point of view. However, minocycline has been reported to reduce inflammatory activation in schizophrenic adults ${ }^{59}$ and agents that target inflammatory processes are being considered for the treatment of depression. ${ }^{60-62}$

The present study has certain limitations. We used two measures to assess deregulation of the immune system (IL-10 and IL-6), but other markers are available. However, much research on neuroinflammation has been based on changes in IL-6 and IL-10. ${ }^{63-66}$ Our sample comprised pregnant polydrug users. This increases the external validity of the study and, the data were adjusted for use of other substances in multivariate analysis. However, because of the size of the sample, the study does not have enough power to isolate all the factors that could influence inflammation response. Additionally, information about drug use was collected by retrospective interview, and is therefore subject to recall bias. We could not evaluate many of the crack/ cocaine using women at delivery time (lost to the sample); however, we made a careful chart review to analyze the loss profile, concluding that we probably lost the most severe cases (type II error). We did not measure maternal body mass index (BMI). While BMI is a good measure for the pre-gestational stage, it is not clinically useful when data collection takes place at the time of delivery, as in our study. Also, the method of blood collection did not account for time of day or time in a fasting state, which are factors that could influence cytokine values. Additionally, it is important to remember that we are dealing with a difficult-to-reach population of 
women who received, for instance, zero or incomplete prenatal care. Finally, since this is a cross-sectional study, it cannot be used to establish causal relationships.

\section{Conclusion}

This study found elevated markers of inflammatory activation in the UCB of newborns with a history of crack/cocaine exposure in utero and in peripheral blood samples from their mothers when compared to nonexposed controls. These changes can be regarded as neurobiological markers, which represent a link between neurodevelopmental and clinical changes. Confirmation of these findings in future studies could be used to support preventive intervention strategies that target the immune system of the newborn, perhaps improving prognosis as a result.

\section{Reference}

1. Lester BM, Tronick EZ, LaGasse L, Seifer R, Bauer CR, Shankaran $S$, et al. The maternal lifestyle study: effects of substance exposure during pregnancy on neurodevelopmental outcome in 1-month-old infants. Pediatrics. 2002;110:1182-92.

2. Min MO, Minnes S, Lang A, Weishampel P, Short EJ, Yoon S, et al. Externalizing behavior and substance use related problems at 15 years in prenatally cocaine exposed adolescents. J Adolesc. 20144;37:269-.

3. Richardson GA, Goldschmidt L, Larkby C, Day NL. Effects of prenatal cocaine exposure on child behavior and growth at 10 years of age. Neurotoxicol Teratol. 2013;40:1-8.

4. Meyer KD, Zhang L. Short- and long-term adverse effects of cocaine abuse during pregnancy on the heart development. Ther Adv Cardiovasc Dis. 2009;3:7-16.

5. LaGasse LL, Gaskins RB, Bada HS, Shankaran S, Liu J, Lester BM, et al. Prenatal cocaine exposure and childhood obesity at nine years. Neurotoxicol Teratol. 2011;33:188-97.

6. Shankaran S, Bann CM, Bauer CR, Lester BM, Bada HS, Das A, et al. Prenatal cocaine exposure and BMI and blood pressure at 9 years of age. J Hypertens. 2010;28:1166-75.

7. Coussens LM, Werb Z. Inflammation and cancer. Nature. 2002;420:860-7.

8. Dandona $P$, Aljada A, Bandyopadhyay A. Inflammation: the link between insulin resistance, obesity and diabetes. Trends Immunol. 2004;25:4-7.

9. Hansson GK. Inflammation, atherosclerosis, and coronary artery disease. N Engl J Med. 2005;352:1685-95

10. Kiecolt-Glaser JK, Gouin JP, Hantsoo L. Close relationships, inflammation, and health. Neurosci Biobehav Rev. 2010;35:33-8.

11. Libby $P$, Ridker PM, Maseri A. Inflammation and atherosclerosis. Circulation. 2002;105:1135-43.

12. Lin WW, Karin M. A cytokine-mediated link between innate immunity, inflammation, and cancer. J Clin Invest. 2007;117:1175-83.

13. Pickup JC. Inflammation and activated innate immunity in the pathogenesis of type 2 diabetes. Diabetes Care. 2004;27:81323.

14. Tian R, Hou G, Li D, Yuan TF. A possible change process of inflammatory cytokines in the prolonged chronic stress and its ultimate implications for health. ScientificWorldJournal. 2014:2014:780616.

15. Sinha R. How does stress increase risk of drug abuse and relapse? Psychopharmacology (Berl). 2001;158:343-59.

16. Fox HC, D'Sa C, Kimmerling A, Siedlarz KM, Tuit $K L$, Stowe $R$, et al. Immune system inflammation in cocaine dependent individuals: implications for medications development. Hum Psychopharmacol. 2012;27:156-66.
17. Narvaez JC, Magalhães PV, Fries GR, Colpo GD, Czepielewski LS, Vianna $\mathrm{P}$, et al. Peripheral toxicity in crack cocaine use disorders. Neurosci Lett. 2013;544:80-4.

18. De Giovanni N, Marchetti D. Cocaine and its metabolites in the placenta: a systematic review of the literature. Reprod Toxicol. 2012;33:1-14.

19. Riezzo I, Fiore C, De Carlo D, Pascale N, Neri M, Turillazzi E, et al. Side effects of cocaine abuse: multiorgan toxicity and pathological consequences. Curr Med Chem. 2012;19:5624-46.

20. Eiden RD, Veira Y, Granger DA. Prenatal cocaine exposure and infant cortisol reactivity. Child Dev. 2009;80:528-43.

21. Brown JV, Bakeman R, Coles CD, Platzman KA, Lynch ME. Prenatal cocaine exposure: a comparison of 2-year-old children in parental and nonparental care. Child Dev. $2004 ; 75: 1282-95$.

22. Karlix JL, Behnke M, Davis-Eyler F, Wobie K, Adams V, Freiburger $B$, et al. Cocaine suppresses fetal immune system. Pediatr Res. 1998;44:43-6.

23. Diesner SC, Förster-Waldl E, Olivera A, Pollak A, Jensen-Jarolim $\mathrm{E}$, Untersmayr E. Perspectives on immunomodulation early in life. Pediatr Allergy Immunol. 2012;23:210-23.

24. Chatterjee $P$, Chiasson VL, Bounds KR, Mitchell BM. Regulation of the anti-inflammatory cytokines interleukin-4 and interleukin-10 during pregnancy. Front Immunol. 2014;5:253.

25. Foundation for the Accreditation of Cellular Therapy (FACT); International Netcord Foundation. NetCord-FACT International Standards for Cord Blood Collection, Banking, and Release for Administration. 5th ed. Omaha: University of Nebraska Medical Center; 2013.

26. Nascimento E do, Figueiredo VLM de. WISC-III e WAIS-III: alterações nas versões originais americanas decorrentes das adaptações para uso no Brasil. Psicol Reflex Crit. 2002;15:60312.

27. Wechsler D. WAIS-III - Escala de inteligência Wechsler para adultos. São Paulo: Casa do Psicólogo; 2004.

28. Amorim P. Mini International Neuropsychiatric Interview (MINI): validação de entrevista breve para diagnóstico de transtornos mentais. Rev Bras Psiquiatr. 2000;22:106-15.

29. Henrique IF, De Micheli D, Lacerda RB, Lacerda LA, Formigoni ML. [Validation of the Brazilian version of Alcohol, Smoking and Substance Involvement Screening Test (ASSIST)]. Rev Assoc Med Bras. 2004;50:199-.

30. Szobot CM, Rohde LA, Bukstein O, Molina BS, Martins C, Ruaro $P$, et al. Is attention-deficit/hyperactivity disorder associated with illicit substance use disorders in male adolescents? A communitybased case-control study. Addiction. 2007;102:1122-30.

31. Mattar FN. Análise crítica dos estudos de estratificação sócioeconômicada ABA-Abipeme. Rev Adm. 1995;30:57-74.

32. Manrique-Garcia E, Zammit S, Dalman C, Hemmingsson T, Andreasson S, Allebeck P. Cannabis, schizophrenia and other non-affective psychoses: 35 years of follow-up of a populationbased cohort. Psychol Med. 2012;42:1321-8.

33. Hermida-Ameijeiras A, Méndez-Alvarez E, Sánchez-Iglesias S, Sanmartín-Suárez C, Soto-Otero R. Autoxidation and MAOmediated metabolism of dopamine as a potential cause of oxidative stress: role of ferrous and ferric ions. Neurochem Int. 2004;45:103-16.

34. Smythies J, Galzigna L. The oxidative metabolism of catecholamines in the brain: a review. Biochim Biophys Acta. 1998;1380:159-62.

35. Vaziri ND. Causal link between oxidative stress, inflammation, and hypertension. Iran J Kidney Dis. 2008;2:1-10.

36. Haroon E, Raison CL, Miller AH. Psychoneuroimmunology meets neuropsychopharmacology: translational implications of the impact of inflammation on behavior. Neuropsychopharmacology. 2012;37:137-62.

37. Dantzer R. Cytokine, sickness behavior, and depression. Immunol Allergy Clin North Am. 2009;29:247-64.

38. Sternberg EM. Neural regulation of innate immunity: a coordinated nonspecific host response to pathogens. Nat Rev Immunol. 2006;6:318-28.

39. Leckman JF. Commentary: What does immunology have to do with brain development and psychopathology?--a commentary on O'Connor et al. (2014). J Child Psychol Psychiatry. 2014;55:632-4.

40. O'Connor TG, Moynihan JA, Caserta MT. Annual research review: the neuroinflammation hypothesis for stress and psychopathology in children--developmental psychoneuroimmunology. J Child Psychol Psychiatry. 2014;55:615-31.

41. Glover V. Prenatal stress and its effects on the fetus and the child: possible underlying biological mechanisms. Adv Neurobiol. 2015;10:269-83. 
42. Cheng $\mathrm{CY}$, Pickler RH. Perinatal stress, fatigue, depressive symptoms, and immune modulation in late pregnancy and one month postpartum. ScientificWorldJournal. 2014;2014:652630.

43. Coussons-Read ME, Okun ML, Nettles CD. Psychosocial stress increases inflammatory markers and alters cytokine production across pregnancy. Brain Behav Immun. 2007; 21:343-50.

44. Ruiz RJ, Fullerton J, Dudley DJ. The interrelationship of maternal stress, endocrine factors and inflammation on gestational length. Obstet Gynecol Surv. 2003;58:415-28.

45. Delaney-Black V, Covington C, Nordstrom B, Ager J, Janisse J, Hannigan $\mathrm{JH}$, et al. Prenatal cocaine: quantity of exposure and gender moderation. J Dev Behav Pediatr. 2004;25:254-63.

46. Nordstrom Bailey B, Sood BG, Sokol RJ, Ager J, Janisse J, Hannigan $\mathrm{JH}$, et al. Gender and alcohol moderate prenatal cocaine effects on teacher-report of child behavior. Neurotoxicol Teratol. 2005;27:181-9.

47. Kiecolt-Glaser JK, Gouin JP, Weng NP, Malarkey WB, Beversdorf DQ, Glaser R. Childhood adversity heightens the impact of laterlife caregiving stress on telomere length and inflammation. Psychosom Med. 2011;73:16-22.

48. Lester BM, Padbury JF. Third pathophysiology of prenatal cocaine exposure. Dev Neurosci. 2009;31:23-35

49. Tyrka AR, Burgers DE, Philip NS, Price LH, Carpenter LL. The neurobiological correlates of childhood adversity and implications for treatment. Acta Psychiatr Scand. 2013;128:434-47.

50. Sadri-Vakili G. Cocaine triggers epigenetic alterations in the corticostriatal circuit. Brain Res. 2015;1628:50-9.

51. Baune BT, Konrad C, Grotegerd D, Suslow T, Birosova E, Ohrmann $P$, et al. Interleukin-6 gene (IL-6): a possible role in brain morphology in the healthy adult brain. J Neuroinflammation. 2012;9:125.

52. Marsland AL, Gianaros PJ, Abramowitch SM, Manuck SB, Hariri AR. Interleukin-6 covaries inversely with hippocampal grey matter volume in middle-aged adults. Biol Psychiatry. 2008;64:484-90.

53. Bandstra ES, , Morrow CE, Vogel AL, Fifer RC, Ofir AY, Dausa AT, et al. Longitudinal influence of prenatal cocaine exposure on child language functioning. Neurotoxicol Teratol. 2002;24:297-308.

54. Delaney-Black V, Covington C, Templin T, Kershaw T, NordstromKlee B, Ager J, et al. Expressive language development of children exposed to cocaine prenatally: literature review and report of a prospective cohort study. J Commun Disord. 2000;33:463-80; quiz 480-1.

55. Eyler FD, Behnke M, Conlon M, Woods NS, Wobie K. Birth outcome from a prospective, matched study of prenatal crack/cocaine use: II. Interactive and dose effects on neurobehavioral assessment. Pediatrics. 1998;101:237-41.

56. Potter SM, Zelazo PR, Stack DM, Papageorgiou AN. Adverse effects of fetal cocaine exposure on neonatal auditory information processing. Pediatrics. 2000;105:E40.
57. Singer $L T$, Arendt R, Minnes S, Farkas K, Salvator A, Kirchner HL, et al. Cognitive and motor outcomes of cocaine-exposed infants. JAMA. 2002;287:1952-60.

58. Baraban SC, Schwartzkroin PA. Effects of prenatal cocaine exposure on the developing hippocampus: intrinsic and synaptic physiology. J Neurophysiol. 1997;77:126-36.

59. Chaudhry IB, Hallak J, Husain N, Minhas F, Stirling J, Richardson $P$, et al. Minocycline benefits negative symptoms in early schizophrenia: a randomised double-blind placebo-controlled clinical trial in patients on standard treatment. J Psychopharmacol. 2012;26:1185-93.

60. Lotrich FE, Sears B, McNamara RK. Elevated ratio of arachidonic acid to long-chain omega-3 fatty acids predicts depression development following interferon-alpha treatment: relationship with interleukin-6. Brain Behav Immun. 2013;31:48-53.

61. Miyaoka $T$, Wake $R$, Furuya $M$, Liaury $K$, Ieda M, Kawakami $\mathrm{K}$, et al. Minocycline as adjunctive therapy for patients with unipolar psychotic depression: an open-label study. Prog Neuropsychopharmacol Biol Psychiatry. 2012;37:222-6.

62. Raison $C L$, Rutherford RE, Woolwine BJ, Shuo C, Schettler P, Drake $\mathrm{DF}$, et al. A randomized controlled trial of the tumor necrosis factor antagonist infliximab for treatment-resistant depression: the role of baseline inflammatory biomarkers. JAMA Psychiatry. 2013;70:31-41.

63. Carpenter LL, Gawuga CE, Tyrka AR, Lee JK, Anderson GM, Price $\mathrm{LH}$. Association between plasma IL- 6 response to acute stress and early-life adversity in healthy adults. Neuropsychopharmacology. 2010;35:2617-23.

64. Mesquita AR, Correia-Neves M, Roque S, Castro AG, Vieira $P_{,}$ Pedrosa J, et al. IL-10 modulates depressive-like behavior. J Psychiatr Res. 2008;43:89-97.

65. Meyer U, Murray PJ, Urwyler A, Yee BK, Schedlowski M, Feldon J. Adult behavioral and pharmacological dysfunctions following disruption of the fetal brain balance between pro-inflammatory and IL-10-mediated anti-inflammatory signaling. Mol Psychiatry. 2008; $13: 208-21$.

66. Sukoff Rizzo SJ, Neal SJ, Hughes ZA, Beyna M, RosenzweigLipson S, Moss SJ, et al. Evidence for sustained elevation of IL-6 in the CNS as a key contributor of depressive-like phenotypes. Transl Psychiatry. 2012;2:e199.

\section{Correspondence:}

Victor Mardini

Rua Ramiro Barcelos, 2350, sala 400

90035-903 - Porto Alegre, RS - Brazil

Tel. : +55 (51) 3359.8413/8294

E-mail:vmardini@hcpa.edu.br 